\title{
Investigation on Evaluation of a Solar Intermittent Refrigeration System for Ice Production with Ammonia/Calcium Chloride and Activated
}

\author{
Hamid R. Goshayeshi, Mehdi Gewad, Hojat Nazari \\ Department of Mechanical Engineering, Mashhad Branch, Islamic Azad University, Mashhad, Iran \\ Email: goshayshi@yahoo.com
}

Received 30 July 2015; accepted 7 September 2015; published 10 September 2015

Copyright (C) 2015 by authors and Scientific Research Publishing Inc.

This work is licensed under the Creative Commons Attribution International License (CC BY). http://creativecommons.org/licenses/by/4.0/

(c) () Open Access

\begin{abstract}
Experimental results of an intermittent solar absorption cooling system using parabolic collector are presented in this paper. The system used $6 \mathrm{~kg}$ of ammonia as refrigerant, $6 \mathrm{~kg}$ of calcium chloride as absorbent and $2 \mathrm{~kg}$ activated carbon as a solvent. The generator temperature was found to be $105^{\circ} \mathrm{C}$. The system could produce ice at $-16^{\circ} \mathrm{C}$ on the average. These are the most advanced results for a solar ice maker so far. All these successful achievements will speed up the commercial processing of a solar ice maker.
\end{abstract}

\section{Keywords}

Intermittent Absorption Cooling System, Solar Energy, Parabolic Collector, Solid Absorbent

\section{Introduction}

In the last four decades, many researchers focused on the technologies for freezing conditions with evaporation temperature below $0^{\circ} \mathrm{C}$. To achieve that, extensive investigations on the performance of adsorption refrigeration have been conducted considering various adsorbent/refrigerant pairs, such as activated carbon/ammonia [1] [2], zeolite/water [3], activated carbon/methanol [4] and silica gel/water [5]. Most of investigators used ammonia for their work. The commonly used $\mathrm{CaCl}_{2}$ for adsorption refrigeration is mainly $\mathrm{CaCl}_{2}$, but there are two problems for $\mathrm{CaCl}_{2}$ that needs to be considered. One is the high desorption temperature compared with physical adsorbent, and the other is the deterioration of mass transfer performance due to agglomeration. For solving the first problem, we can use large parabolic collector and also by electrical simulation heating or using exhausting gases of 
engines or industrial waste heat to provide a heat source at about $110^{\circ} \mathrm{C}$ to $150^{\circ} \mathrm{C}$ [6]. For solving the second problem related to mass transfer performance in chemical adsorption bed, using the composite adsorbents would be the best choice [7]. Activated carbon can provide the micro mass transfer channels to calcium chloride because it has abundant micro pores and therefore can increase the mass transfer coefficient of calcium chloride. The best mass ratio between calcium chloride and activated carbon was studied by some researchers such as [8]-[10].

The working system of activated carbon/ammonia pair was developed by Miles and Shelton [4]. For evaporation temperatures equal to or below $0^{\circ} \mathrm{C}$, activated carbon is the physical adsorbent most employed [2]-[5]. Wang et al. [11] mixed $\mathrm{CaCl}_{2}$ with activated carbon, and they avoided the agglomeration and obtained constant adsorption capacity and they found that the best ratio of $\mathrm{CaCl}_{2}$ to activated carbon was in ratio of 4 to 1 in mass [8]. In this paper, the ratio of $\mathrm{CaCl}_{2}$ to activated carbon had been investigated and we found that the best result can be achieved when the ratio of $\mathrm{ClCl}_{2}$ to activated carbon was in ratio of 3.5 to 1 in mass.

\section{Experimental Setup}

Figure 1 shows the intermittent solar absorption cooling system in this study. The parabolic trough was made of $1.2 \times 2.4 \mathrm{~m}^{2}$ acrylic mirror plates. The focus length was $0.5 \mathrm{~m}$. The absorber tube acting as the generator and the absorber was made of a 4 -in steel pipe of $2.4 \mathrm{~m}$ long. The condenser was fabricated from a 0.25 -in steel pipe of $6 \mathrm{~m}$ long coiled inside a 20-litters tank filled with water. The evaporator was made of two 4-in steel pipes of 0.5 $\mathrm{m}$ long each placed inside an insulated tank. The tank was filled with $3 \mathrm{~kg}$ of water to be the cooling load of the system. As it shown in Figure 2 the desorbed refrigerant vapor will be condensed into liquid via the condenser and flows into the evaporator directly. This process lasts until the temperature of adsorbent reaches the maximum desorption temperature. During the night, when the temperature of adsorbent bed reduces, the refrigerant vapor from evaporator gets adsorbent back in the bed. According to Figure 3 during this adsorption process, the cooling effect is released from refrigerant evaporation, and the ice is formed in the water tank placed inside thermal insulated water box.

Ammonia/calcium chloride pair was selected to be the working substances because they are readily available in the market, not expensive, and work at a pressure higher than the atmospheric pressure. This is advantageous since leakage could be detected more easily compared to the use of water as refrigerant where the system would have to work in the vacuum pressure range.

Experimental results showed that the expanded graphite avoided agglomeration of the salt and produced a compound with stable absorption capacity $0.90 \mathrm{~kg}$ of $\mathrm{NH}_{3}$ per $\mathrm{kg}$ of $\mathrm{CaCl}_{2}$.

By considering together with the property diagram of the working pair, it was found that $6 \mathrm{~kg}$ of ammonia and $6 \mathrm{~kg}$ of calcium chloride were required for the system operation.

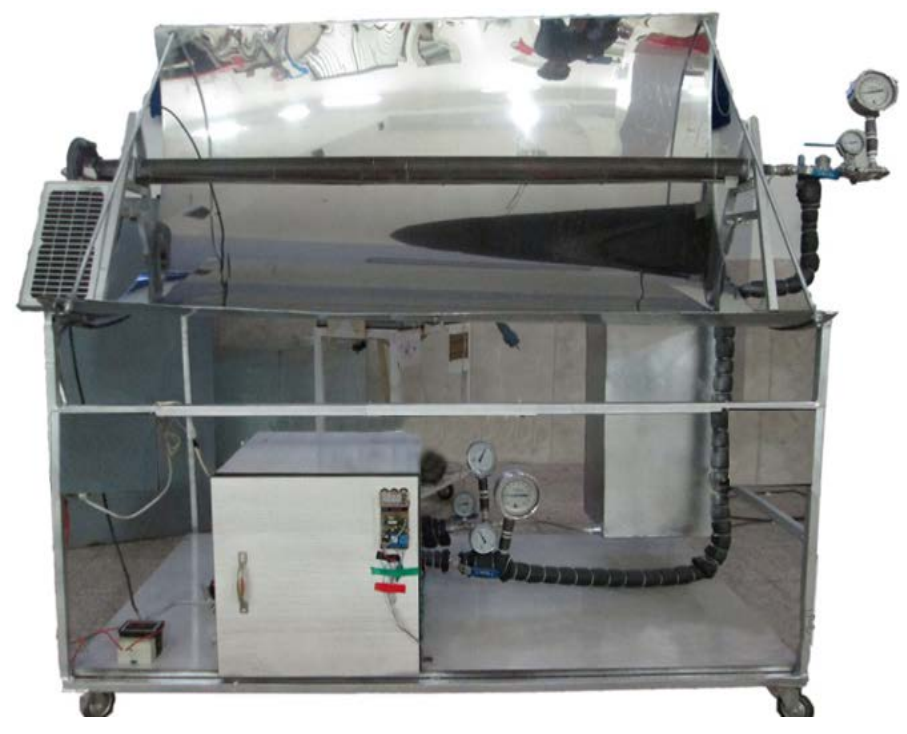

Figure 1. Instrumentation of the solar refrigeration system. 


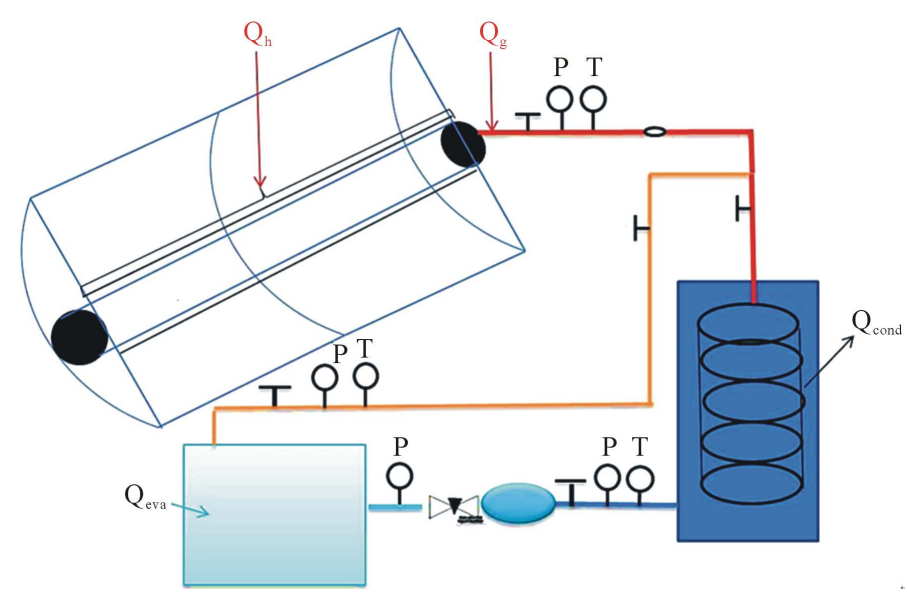

Figure 2. Schematic diagram of the solar intermittent absorption refrigeration system.

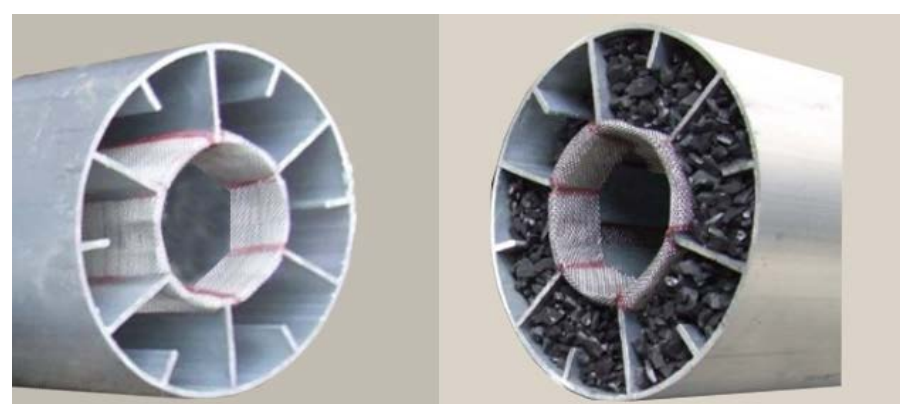

Figure 3. Shows details of the design, construction and test performance of the adsorbent bed.

Several other studies [7]-[9] showed that the activated carbon when employed as inter material could avoid the agglomeration of the salt and improve the heat and mass in the reactive bed of chemical heat pumps. According to the previous researchers [9]-[13], the best mass ratio between $\mathrm{CaCl}_{2}$ and Activated carbon is 4 to 1 .

It is known that the adsorbers must be heated and cooled discontinuously to realize the decomposition (corresponding to the desorption process) and combination (corresponding to the adsorption process) processes between adsorbent ( $\mathrm{CaCl}_{2}$ in this paper) and refrigerant (ammonia in this paper). So the adsorbers will be in desorption and adsorption processes alternately and discontinuously.

The adsorbent bed absorbs solar radiation energy, which raises the temperature of adsorbent as well as the pressure of refrigerant in adsorbent bed during the process. When the temperature of adsorbent reaches the desorption temperature, the adsorbent begins to evaporate from the circular bed. Cross section of absorber tube has been shown in Figure 4.

As it shown in Figure $5 \mathrm{CaCl}_{2}$ mixed with activated carbon to avoid the agglomeration and obtained constant adsorption capacity and according to previous investigator the best ratio of $\mathrm{CaCl}_{2}$ to activated carbon is in ratio of 4 to 1 in mass. In our experiment a mixture of $\mathrm{CaCl}_{2}$ and activated carbon with mass ratio of 3.5 to 1 performed a cooling density $35 \%$ higher than obtained by the use of powder $\mathrm{CaCl}_{2}$.

\section{Result and Discussion}

In this paper a small solar adsorption refrigerator was built and tested under preliminary level (Figure 6). The collector area $1.4 \mathrm{~m}^{2}$ contains $17 \mathrm{~kg}$ of active carbon and $1.60 \mathrm{~kg}$ of ammonia was tested for $150^{\circ} \mathrm{C}$ heat source temperature. It produced up to $4 \mathrm{~kg}$ of ice per day. From the investigation, COP increases first with increase in adsorbent mass and then the COP decreases. The reason is that the increase in adsorbent mass induces high adsorption of ammonia initially in adsorption phase and then desorption of large amounts of ammonia in subsequent desorption process. When considering the adsorption capacity, metallic salts are a better alternative than 


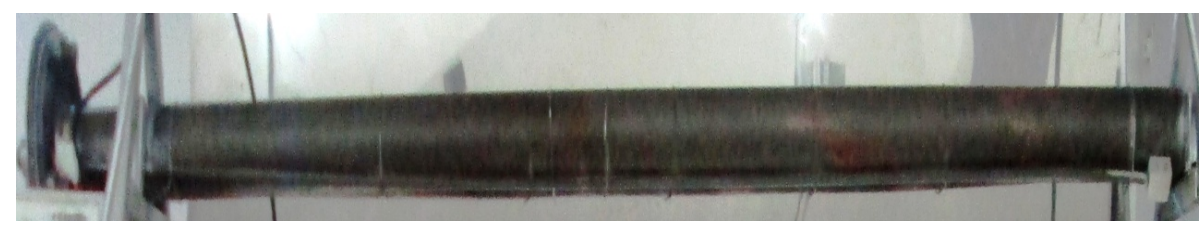

Figure 4. Photograph of Absorber tube.

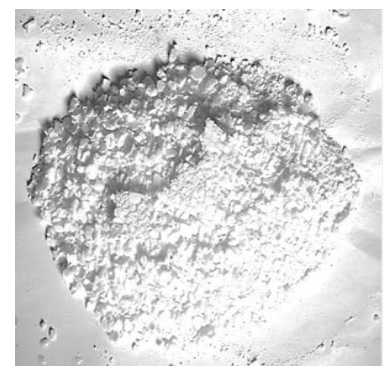

(a)

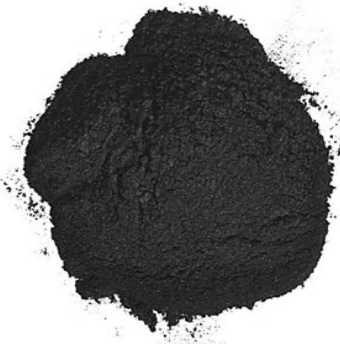

(b)

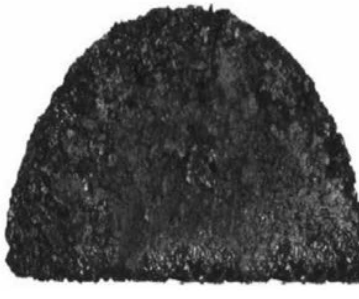

(c)

Figure 5. Solidified compound: (a) $\mathrm{CaCl}_{2}$ powder; (b) Active Carbon; (c) mixed.
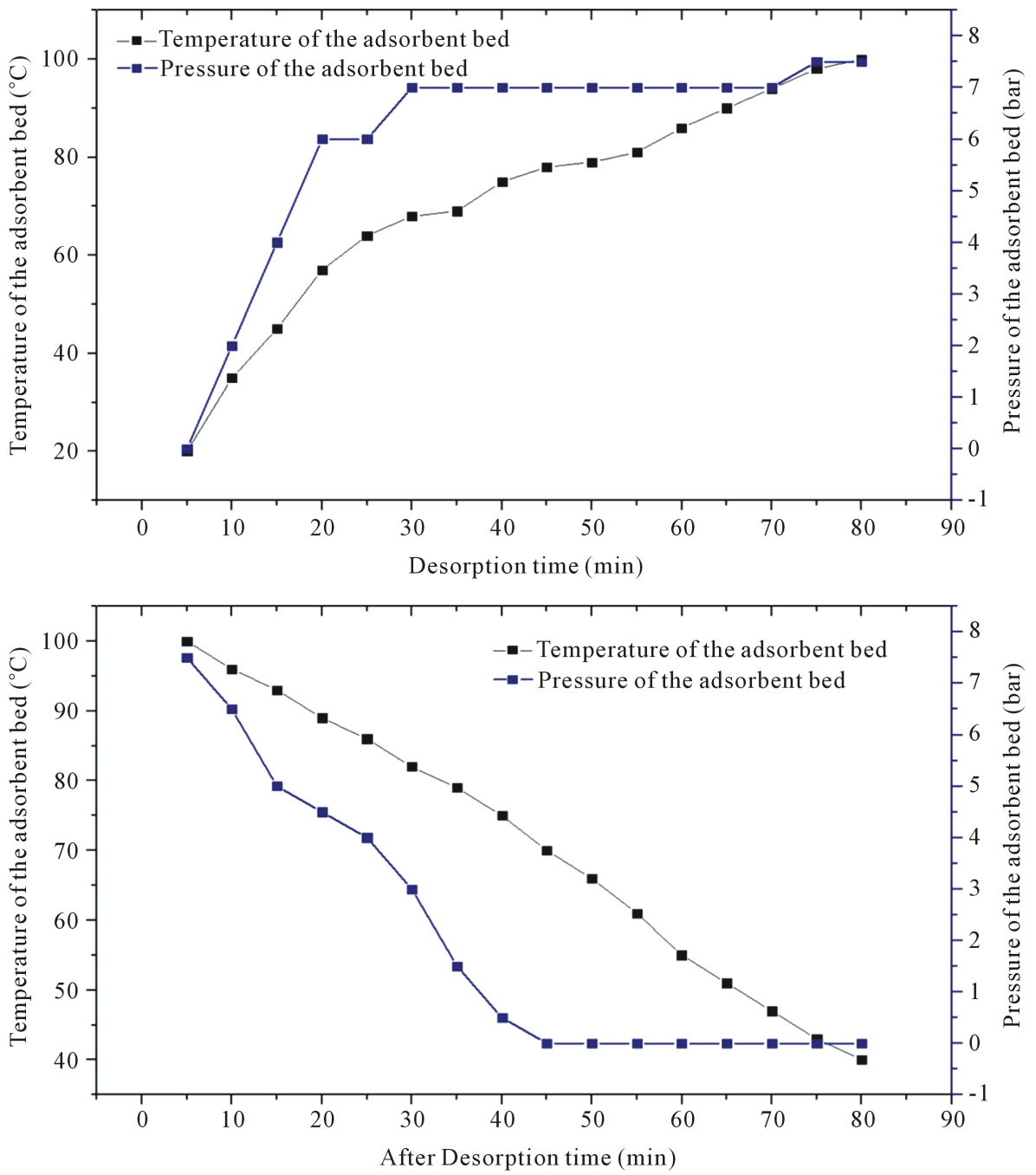

Figure 6. The variation of Temperature of adsorption and pressure of adsorption. 
the physical adsorbents [12]. However, salts and granular physical adsorbents have low thermal conductivity, which increase the reaction time and decrease the specific cooling power. Furthermore, salts may agglomerate after consecutives decompositions and synthesis, which can reduce the conversion capacity [13]. However, the practical difficulties and disadvantages of activated active carbon/ammonia systems are the high pressure requirement and the corrosive nature of the refrigerant (ammonia). The problem of the bulky large systems can be avoided by the development of rapid cycling units. Furthermore, salts may agglomerate after consecutives decompositions and synthesis, which can reduce the conversion capacity (Figure 7).

In our experiment a mixture of $\mathrm{CaCl}_{2}$ and activated carbon with mass ratio of 3.5 to 1 according to Figure 8 performed a cooling density $35 \%$ higher than obtained by the use of powder $\mathrm{CaCl}_{2}$.

Figure 9 shows a typical evaporation process. The process began at night time. The evaporator inlet temperature $\mathrm{T}_{\mathrm{El}}$ felt down drastically at temperatures as low as $-16^{\circ} \mathrm{C} . \mathrm{T}_{\mathrm{WE}}$ indicates the temperature of water inside the evaporator that is converted into ice. At the beginning the water temperature decreases and the remains constant because of the change phase. The outlet temperature of the evaporator is similar to the temperature of the air inside of the evaporator, indicating vapor transfers all the available heat to the evaporator.

The addition of activated carbon in $\mathrm{CaCl}_{2}$ could solve the problem of agglomeration and the best result can be achieved by the ratio of $\mathrm{CaCl}_{2}$ to activated carbon to 3.5 to 1 in mass. The $\mathrm{CaCl}_{2}$ is mixed with activated carbon after being dissolved with water and then is dried for experiments.

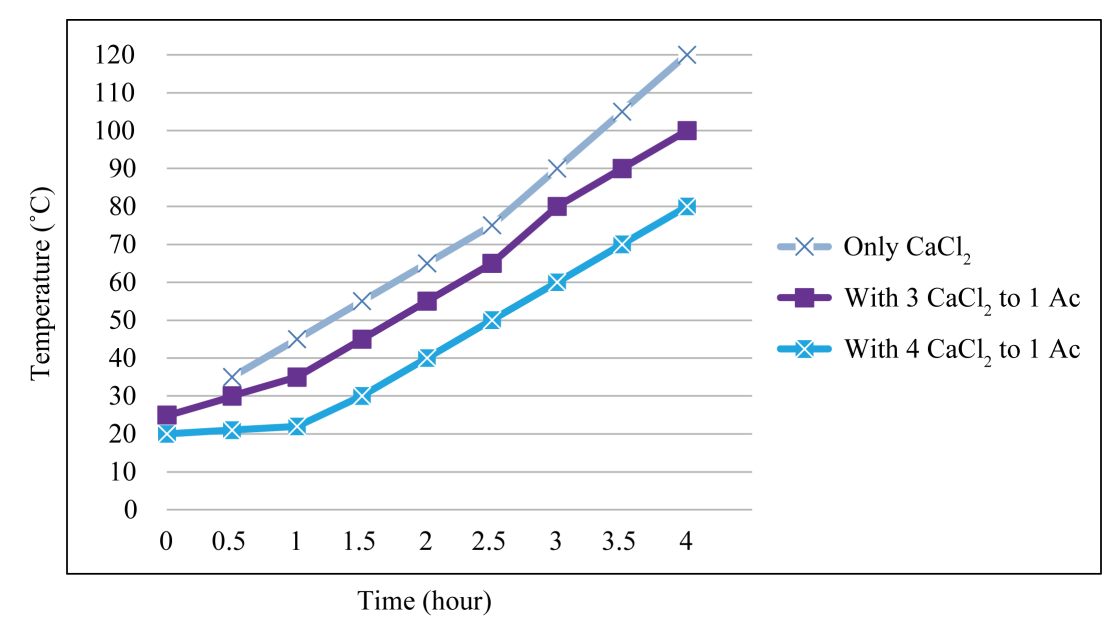

Figure 7. Adsorbent bed temperature evolution with and without activated carbon.

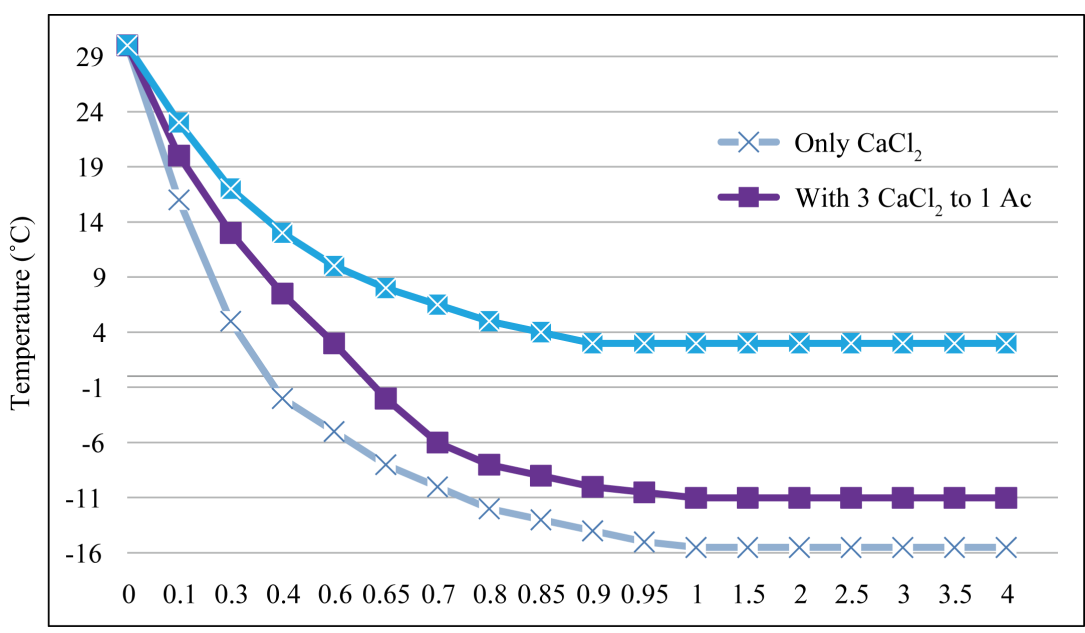

Time (hour)

Figure 8. Evaporator temperature and pressure evolution with and without activated carbon. 


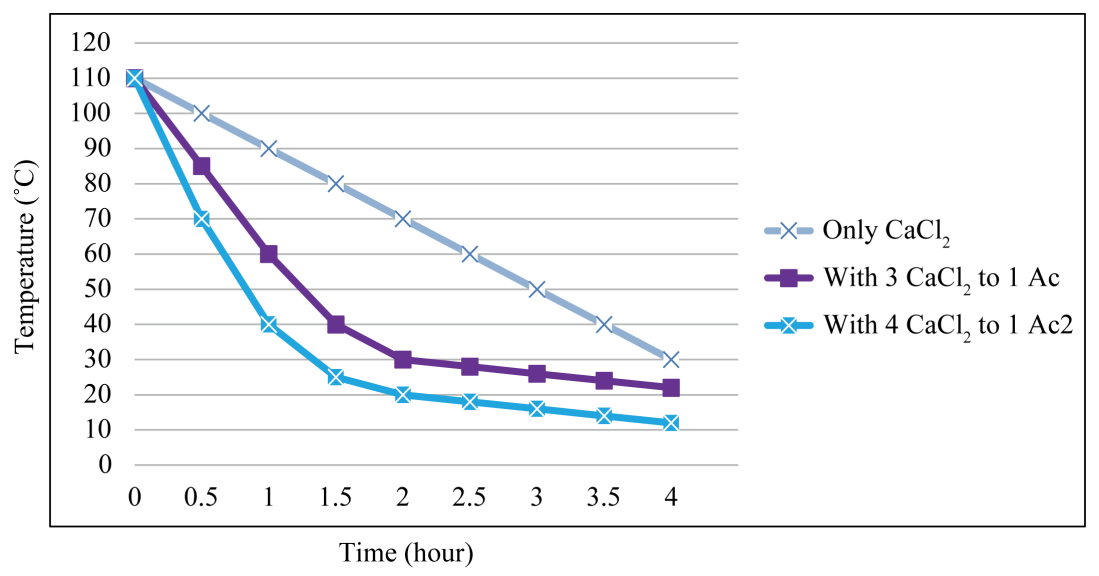

Figure 9. An evaporation process with and without activated carbon.

\section{Conclusions}

A new type of adsorption icemaker driven by PTC which uses a compound adsorbent with different ratio of ammonia and activated carbon is proposed. The experiments of the icemaker have been carried out powered by both solar energy and electrical simulation heating. As the experimental results shown, the highest COP of the adsorption icemaker can reach 0.15 when the desorption temperature, the evaporator temperature can reach $-16^{\circ} \mathrm{C}$

The intermittent solar absorption cooling system in this work obtained heat from a parabolic trough solar collector equipped with a simple solar tracking system. The working substances were $6 \mathrm{~kg}$ of ammonia and $6 \mathrm{~kg}$ of calcium chloride. The experiments were done during summer. On the average, the system could provide cooling capacity of $2.18 \mathrm{MJ}$ at refrigeration COP of 0.1 . The generator temperature was $110^{\circ} \mathrm{C}$. The evaporator temperature was $-16^{\circ} \mathrm{C}$. The cooling capacity is fairly related to the solar heat input and the clearness of the sky.

A novel solar intermittent refrigeration system for ice production operating with the ammonia/calcium chloride mixture has been developed. Evaporator temperatures as low as $-16^{\circ} \mathrm{C}$ were obtained for several hours with solar coefficients of performance up to 0.1. It was found that the solar coefficient of performance increased with the increment of solar radiation and the solution concentration. A dependency of the coefficient of performance was not found against the cooling water temperature. Also it was found that the maximum operating pressure increased and the initial generation temperature decreased with an increase of the solution concentration. The developed system showed to be a good technological for ice production where electricity supply is available to increase the adsorber temperature.

In our experiment, a mixture of $\mathrm{CaCl}_{2}$ and activated carbon with mass ratio of 3.5 to 1 performed a cooling density $35 \%$ higher than obtained by the use of powder $\mathrm{CaCl}_{2}$.

\section{Acknowledgements}

This research was supported by Islamic Mashhad Azad University with grant number of 62115 . The authors would like to express their sincere appreciation for all support provided by this university.

\section{References}

[1] Critoph, R.E. (1994) An Ammonia Carbon Solar Refrigerator for Vaccine Cooling. Renewable Energy, 5, 502-508. http://dx.doi.org/10.1016/0960-1481(94)90424-3

[2] Critoph, R.E. (1996) Evaluation of Alternative Refrigerant-Adsorbent Pairs for Refrigeration Cycles. Applied Thermal Engineering, 16, 891-900. http://dx.doi.org/10.1016/1359-4311(96)00008-7

[3] El Fadar, A., Mimet, A. and Pérez-García, M. (2009) Study of an Adsorption Refrigeration System Powered by Parabolic Trough Collector and Coupled with a Heat Pipe. Renewable Energy, 34, 2271-2279. http://dx.doi.org/10.1016/j.renene.2009.03.009

[4] Miles, D. and Shelton, S. (1996) Design and Testing of a Solid-Sorption Heat-Pump System. Applied Thermal Engineering, 16, 389-394. http://dx.doi.org/10.1016/1359-4311(95)00021-6 
[5] Tamainot-Telto, Z. and Critoph, R.E. (1997) Adsorption Refrigerator Using Monolithic Carbon-Ammonia Pair. International Journal of Refrigeration, 20, 146-155. http://dx.doi.org/10.1016/S0140-7007(96)00053-9

[6] Lu, Z.S., Wang, R.Z., Li, T.X., Wang, L.W. and Chen, C.J. (2007) Experimental Investigation of a Novel Multifunction Heat Pipe Solid Sorption Icemaker for Fishing Boats Using $\mathrm{CaCl}_{2} /$ Activated Carbon Compound-Ammonia. International Journal of Refrigeration, 30, 780-790.

[7] Li, C., Wang, R.Z., Wang, L.W., Li, T.X. and Chen, Y. (2013) Experimental Study on an Adsorption Icemaker Driven by Parabolic Trough Solar Collector. Renewable Energy, 57, 223-233. http://dx.doi.org/10.1016/j.renene.2013.01.040

[8] Li, M., Wang, R.Z., Xu, Y.X., Wu, J.K. and Dieng, A.O. (2002) Experimental Study on Dynamic Performance Analysis of a Flat-Plate Solar Solid-Adsorption Refrigeration for Ice Maker. Renew Energy, 27, 211-221. http://dx.doi.org/10.1016/S0960-1481(01)00188-4

[9] Oliver, R.G., Silveira, R.V. and Wang, R.Z. (2005) Experimental Study of Mass Recovery Adsorption Cycles for Ice Making at Low Generation Temperature. Applied Thermal Engineering, 26, 303-311. http://dx.doi.org/10.1016/j.applthermaleng.2005.04.021

[10] Wang, L.W., Wang, R.Z., Wu, J.K., Wang, K. and Wang, S.G. (2004) Adsorption Ice Makers for Fishing Boats Driven by the Exhaust Heat from Diesel Engine: Choice of Adsorption Pair. Energy Convers Manage, 45, 2043-2057. http://dx.doi.org/10.1016/j.enconman.2003.10.021

[11] Wang, R.Z. (2001) Adsorption Refrigeration Research in Shanghai Jiao Tong University. Renewable and Sustainable Energy Reviews, 5, 1-37. http://dx.doi.org/10.1016/S1364-0321(00)00009-5

[12] Wang, L.W., Wang, R.Z., Wu, J.Y. and Wang, K. (2004) Compound Adsorbent for Adsorption Ice Maker on Fishing Boats. International Journal of Refrigeration, 27, 401-408. http://dx.doi.org/10.1016/j.ijrefrig.2003.11.010

[13] Wang, L.W., Wang, R.Z., Wu, J.Y. and Wang, K. (2004) Adsorption Performance of $\mathrm{CaCl}_{2}-\mathrm{NH}_{3}$ and Its Application on Refrigeration. Science China E, 47, 173-185. http://dx.doi.org/10.1360/03ye0248 